Revista de la Escuela de Ciencias de la Educación, año 14, nRo. 13, vol. 2, julio a diciembre de 2018. PÁGINAS 165-168. ISSN 1851-6297 (DESDE DICIEMBRE DE 2006 A DICIEMBRE DE 2017). ISSN $2362-$ 3349 (En linea). Cuando caen las diferencias entre grandes y chicos. Jesús Ismael del Canto.

\title{
CUANDO CAEN LAS DIFERENCIAS ENTRE GRANDES Y CHICOS
}

\author{
Jesús Ismael del Canto* \\ Hospital Álvarez - Gobierno de la ciudad de Buenos Aires, Argentina \\ lic.delcanto@gmail.com
}

\begin{abstract}
Resumen
Este libro condensa el resultado de una investigación que explica una serie de fenómenos contemporáneos relativos a niños/as y adolescentes (problemas de límites, bullying, adolescencias prolongadas) a partir de una ruptura generacional con los adultos. Se trata de un escenario en el cual son las nuevas generaciones las que conducen los cambios en la vida social y la adultez y la acumulación de saber no son valoradas. Esto generaría que los sujetos no quieran crecer y asumir responsabilidades. Esta postergación de las responsabilidades tradicionalmente adultas dejaría a la deriva a los niños/as y adolescentes actuales.
\end{abstract}

Palabras clave: Adultos - Familia - Escuela - Tecnología - Infancias.

\begin{abstract}
This book sums up the results of a research that explains a series of contemporary fenomena related to children and adolescents (caring, bullying, long adolescences) in terms of a generational breaking off with adults. It's a scenery where new generations drive social changes and adulthood and knowledge increasement aren't valued, making therefore that nobody wants to grow up and become responsible. This postponement of responsabilities asociated with adulthood would leave children and adolescents adrift.
\end{abstract}

* Es Licenciado en Trabajo Social con Tramo de Formación Pedagógica para Profesionales y Técnicos Superiores. Diplomado Superior en Metodología de la Investigación - UCES. Diplomado en el Modelo Sistémico, en curso - Escuela Sistémica Argentina. Ex orientador social en la Dirección General de Cultura y Educación de la Provincia de Buenos Aires. Ex residente de Servicio Social en el Hospital Fernández - Gobierno de la Ciudad de Buenos Aires. Actualmente, Asistente Social de Planta en el Hospital Álvarez - Gobierno de la Ciudad de Buenos Aires. 
Revista de la Escuela de Ciencias de la Educación, año 14, nRo. 13, vol. 2, julio a diciembre de 2018. PÁGINAS 165-168. ISSN 1851-6297 (DESDE DICIEMBRE DE 2006 A DICIEMBRE DE 2017). ISSN $2362-$ 3349 (En Linea). Cuando caen las diferencias entre grandes y Chicos. Jesús Ismael del Canto.

Keywords: Adults - Family - School - Technology - Childhoods.

La obra que presenta Mariano Narodowski continúa con algunos planteos e inquietudes ya esbozados en "Infancia y poder" (1994) relativos al rol de la escuela y la emergencia de las llamadas nuevas infancias. En el libro aquí reseñado, se problematizan precisamente las transformaciones en las interacciones adultos-niños/as y adolescentes en la sociedad, haciendo hincapié en la familia, y en la relación entre ésta y el sistema escolar.

Se trata aquí de establecer conexiones causales entre una serie de fenómenos contemporáneos que se presentan como inconexos (incivilidades escolares, problemas de crianza y límites, adolescencias prolongadas, uso de nuevas tecnologías, etc.) pero que según él nos propone, se encuentran estrechamente vinculados en su génesis.

De acuerdo con Narodowski, es central volver a Margaret Mead para comprender qué es lo que sucede y cómo se gesta el malestar actual inter-institucional, a partir de su distinción entre culturas posfigurativas y prefigurativas. Las primeras se caracterizan por ser períodos de cambios lentos, en los cuales se valora la acumulación de saber y experiencia y donde los adultos están a cargo de los niños y adolescentes hasta que éstos estén maduros para tomar el lugar de los primeros.

En contraste, las culturas prefigurativas se destacan por ser escenarios de cambios extremadamente rápidos, donde son las nuevas generaciones las que mejor se adaptan a las exigencias del medio social y por ende la tradición y la acumulación de conocimientos que viene con la edad no son valoradas.

Es por esto mismo que se borran las marcas que separan las edades y por lo cual nadie querría envejecer: porque se trataría de un momento de la vida ligado a la obsolescencia y el descarte, en contraste con la juventud siempre actualizada y vigente Se trata de un proceso acompañado por los medios masivos de comunicación en sus imágenes que encumbran la adolescencia y por una hegemonía lingüística en la cual todas las personas son "chicos/as" y "sin edad" definida.

Siguiendo esta separación de marcos culturales, el autor plantea que el escenario actual ha devenido prefigurativo, en el que las relaciones entre padres e hijos o docentes y alumnos, antes desiguales y complementarias, se han vuelto cada vez más simétricas, generando dificultades en el proceso de socialización.

En efecto el malestar actual del sistema escolar, percibido como falta de capacitación docente en relación con la tecnología o de nostalgia por épocas pasadas, sería otra consecuencia de vivir una época prefigurativa. Respecto a la cuestión de la inclusión de nuevas tecnologías en el ámbito escolar, su auténtica integración de forma eficaz constituye aún un desafío, que por lo demás tampoco resolvería en sí mismo el problema ya explicado de la asimetría de roles. 
Revista de la Escuela de Ciencias de la Educación, año 14, nRo. 13, vol. 2, Julio a diciembre de 2018. PÁGINAS 165-168. ISSN 1851-6297 (DESDE DICIEMBRE DE 2006 A DICIEMBRE DE 2017). ISSN $2362-$ 3349 (En linea). Cuando caen las diferencias entre grandes y chicos. Jesús Ismael del Canto.

Dicho de otro modo, para Narodowski, las preguntas en torno al uso de la televisión y otros dispositivos digitales serían la consecuencia del cambio de eras y no el origen de los obstáculos (como habitualmente se entiende desde el sentido común y algunos sectores de la academia). De acuerdo con la óptica que aquí se viene siguiendo, la percepción de incapacidad de la función socializadora de la escuela y el hecho de que algunos alumnos/as parezcan saber más que sus docentes constituyen también emergentes de la lógica prefigurativa que atraviesa la subjetividad contemporánea.

Asimismo, se ha producido en la relación familia-escuela un giro dramático: mientras que en otros tiempos la segunda siempre "triunfaba" en los conflictos que ocurrieran con la primera (porque el Estado así lo garantizaba), ahora el resultado final de los mismos es incierto. $Y$ es justamente por esta incertidumbre que los docentes en ocasiones acaban teniendo que adaptarse a exigencias de las familias o negociar con sus estudiantes o padres.

Frente a esta coyuntura signada por la ausencia de autoridad adulta, Narodowski apuesta a tratar de instaurar entre viejas y nuevas generaciones asimetrías contingentes y situacionales, relativas a la puesta de reglas, roles de cuidado y crianza, etc. Se trata de una propuesta osada, por cuanto desafía a algunos sectores actuales de la academia que insisten en que los conflictos actuales de la familia y la escuela se deben a la persistencia de estructuras patriarcales verticalistas que no contemplan la diversidad y autonomía juvenil. Por el contrario, "Un mundo sin adultos" invita a pensar la secuencias de modo inverso: debido a la ausencia casi total de autoridad de algún tipo, los niños/as y adolescentes (tanto en lugar de hijos como de alumnos) carecen de modelos y guías que puedan acompañar su crecimiento en algún sentido o dirección.

Ahora bien, la perspectiva de análisis aquí propuesta invita a preguntas relativas a la aparente linealidad de algunas conclusiones del autor, que parecen estar presentadas como deducciones lógicas de sus premisas. Por ejemplo, hasta qué punto la ruptura generada por el cambio de épocas podría acarrear en sí misma la ausencia de asimetría en cuanto a roles de socialización. Es decir, que Mead se refería al acceso al conocimiento de las diferentes generaciones a partir de la velocidad de los cambios, pero cabría preguntarse hasta qué punto las diferencias que se producen entre adultos y niños/as y adolescentes en este aspecto traen en sí mismas problemas con el cuidado, la crianza y la autoridad.

Sea como fuere, se trata de una investigación osada tanto por su sustento teórico como por la originalidad de sus conclusiones. En cuanto al primero, destaca el hecho de que la obra se asienta sobre la pedagogía de Jan Amos Comenius y los trabajos antropológicos de Mead, distanciándose tanto de teorías de alcance macroestructural como del interpretativismo simbólico imperantes. Asimismo, sus fuentes abrevan tanto en recopilación de datos y entrevistas como en diversos soportes textuales de difusión cultural (letras 
Revista de la Escuela de Ciencias de la Educación, año 14, nRo. 13, vol. 2, julio a diciembre de 2018. PÁGINAS 165-168. ISSN 1851-6297 (DESDE DICIEMBRE DE 2006 A DICIEMBRE DE 2017). ISSN 23623349 (En Línea). Cuando caen las diferencias entre grandes y chicos. Jesús Ismael del Canto.

de tangos, literatura, notas periodísticas, etc). En cuanto a las conclusiones, ofrece una óptica que no insiste en democratizar vínculos para favorecer interacciones sino que invita a reinstaurar asimetrías y acuerdos situacionales sobre el cuidado y la crianza.

\section{Referencias bibliográficas}

- Narodowski, M. (1994). Infancia y poder. La conformación de la pedagogía moderna. Buenos Aires: Aique.

- _ (2016). Un mundo sin adultos. Familia, escuela y medios frente a la desaparición de la autoridad de los mayores. Buenos Aires: Debate. 